\title{
Spectrum of glomerular diseases in native kidneys in patients attending Nepal Medical College Teaching Hospital
}

\author{
Manandhar DN, Chhetri PK, Poudel P, Singh N, Baidya SK, Maskey A
}

Department of Nephrology, Nepal Medical College Teaching Hospital, Jorpati, Kathmandu, Nepal.

\section{DOI Name}

http://dx.doi.org/10.3126/jaim.v5i2.17349

\section{Keywords}

Glomerular diseases, native kidney biopsy, Nephrotic syndrome, MCD, lupus nephritis

\section{Citation}

Manandhar DN, Chhetri PK, Poudel P, Singh N, Baidya SK, Maskey A. Spectum of glomerular diseases in native kidneys in patients attending Nepal Medical College Teaching Hospital. Journal of Advances in Internal Medicine 2016;05(02):24-28.

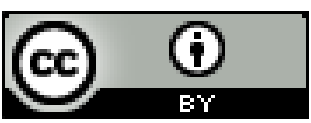

This work is licensed under a Creative Commons Attribution 3.0 Unported License.

\section{ABSTRACT}

Background and Aims: Glomerular disease is the one of the major cause of end stage kidney disease in Nepal. We have undertaken this study to know the spectrum of glomerular disease in native kidneys in patients attending department of nephrology of Nepal Medical College Teaching Hospital.

Methods: This is a retrospective analysis of patients who have undergone native kidney biopsy from July 2013 to June 2014. Seventy five cases were included. We reviewed the biopsy requisition and where available admission forms for symptoms, indications and complications of the biopsy, urine analysis report and final biopsy report. Kidney biopsy was done under USG guidance or assistance. Automated biopsy gun of 16 or $18 \mathrm{G}$ was used. Kidney tissues were sent for light microscopy and immunofluorescence examinations. After $24 \mathrm{hrs}$ of biopsy, USG-KUB and urine RME were repeated for complications

Results: Majority of our study population (62\%) was from age group of 13 to 30 years. Sixty five percent of the patients $(n=49)$ were admitted with a diagnosis of nephrotic syndrome. Most frequent histopathological finding was Minimal Change Disease (26.7\%) followed by LN (21.3\%), Membranous Nephropathy (18.6\%), Focal Segmental Glomerulosclerosis (13.4\%) and IgA nephropathy (9.3\%). Patients with the histopathological diagnosis of LN and IgAN presented with hematuria in $81.2 \%$ and $71.4 \%$ respectively. MCD patients presented with proteinuria only. Total no. of glomeruli in the sample was $23.41 \pm 11.55$.

Conclusion: Nephrotic syndrome was the most common indication for the renal biopsy. MCD was the most common histological finding in our series and Lupus nephritis is not uncommon in our series.

\section{INTRODUCTION}

The prevalence of renal diseases and etiologies of Chronic Kidney Disease (CKD) varies greatly with age, sex, race, geographical distribution and indication of kidney biopsy. Glomerular diseases are one of the major cause for end stage kidney disease. To know the distribution of renal disease, we should take help of kidney biopsy which is a gold standard for the diagnosis. ${ }^{1}$ Kidney biopsy is a relatively safe and an essential procedure to prognosticate and plan the treatment. ${ }^{2}$ The procedure has become safer with life-threatening complications occurring in less than $0.1 \%$ of biopsies ${ }^{3}$ and the yield of obtaining the specimen has increased greatly with

\footnotetext{
* Corresponding author DN Manandhar, Assistant Professor Department of Nephrology Nepal Medical College Teaching Hospital emailid:dhiraj783@gmail.com
} 
the introduction of automated biopsy gun and the procedure being done under the ultrasound guidance. ${ }^{4,5}$ The prevalence of the glomerular disease would differ from one place to another. The prevalence of the kidney disease changes with the time. ${ }^{6}$ We undertook this study to know the spectrum of the glomerular diseases in native kidneys in patients attending department of nephrology of Nepal Medical College Teaching Hospital.

\section{METHODS:}

This is a retrospective analysis of our patients who have undergone native kidney biopsy from July 2013 to June 2014. There were altogether 82 kidney biopsies done during this period. Out of which only 75 cases were included for the study. Seven cases were excluded in the analysis because of inadequate information. We reviewed the biopsy requisition and where available admission forms for the symptoms, indications and complications of the biopsy, urine analysis report and final biopsy report. For the quantification of proteinuria either $24 \mathrm{hrs}$ urinary protein estimation or spot urine for protein creatinine $(P / C)$ ratio was taken. Indications of kidney biopsy were nephrotic syndrome, nephritic syndrome, unexplained Acute Kidney Injury of more than 2 weeks duration and asymptomatic urinary abnormality. In patients with clinical diagnosis of SLE, kidney biopsy was done when urine had proteinuria of more than $500 \mathrm{mg}$ with or without hematuria. Kidney biopsy was done under local anesthesia and under aseptic precautions by a nephrologist or a resident posted in the department. Kidney biopsy was done under USG guidance or assistance with the help of a radiologist. Automated biopsy gun of 16 or $18 \mathrm{G}$ was used. Two pieces of kidney tissues were taken and were sent for histopathological examination for Light microscopy (LM) and Immunofluorescence microscopy (IF). Sample for LM and IF was sent in formalin and normal saline respectively. All the samples were sent to India for histological examination. Patients were admitted for observation and kept in complete bed rest for atleast $24 \mathrm{hrs}$. After $24 \mathrm{hrs}$ of biopsy, USG-KUB and urine RME were repeated for perinephric collection or hematoma and microscopic hematuria. If there was no complication then the patient was discharged after $24 \mathrm{hrs}$ of the procedure.

Statistical Analysis: All the data were compiled in Excel worksheet and Mean, Standard deviations were calculated.

\section{RESULT:}

Out of 82 biopsies, only 75 renal biopsy reports were included in the study as complete information was not available in the rest. There were 42 females in our study. Average age of the study population was $31.32 \pm 11.95$ years. Majority of our study population was from age group of 13 to 30 years (Fig 1). Sixty five percent of the patients $(n=49)$ were admitted with a diagnosis of nephrotic syndrome and $18 \%(n=14)$ with the diagnosis of lupus nephritis (LN). All patients had proteinuria of variable degrees (mean proteinuria of the study sample: $7.23 \pm 5.62 \mathrm{~g})$ and $44 \%(n=33)$ had microscopic hematuria at presentation.

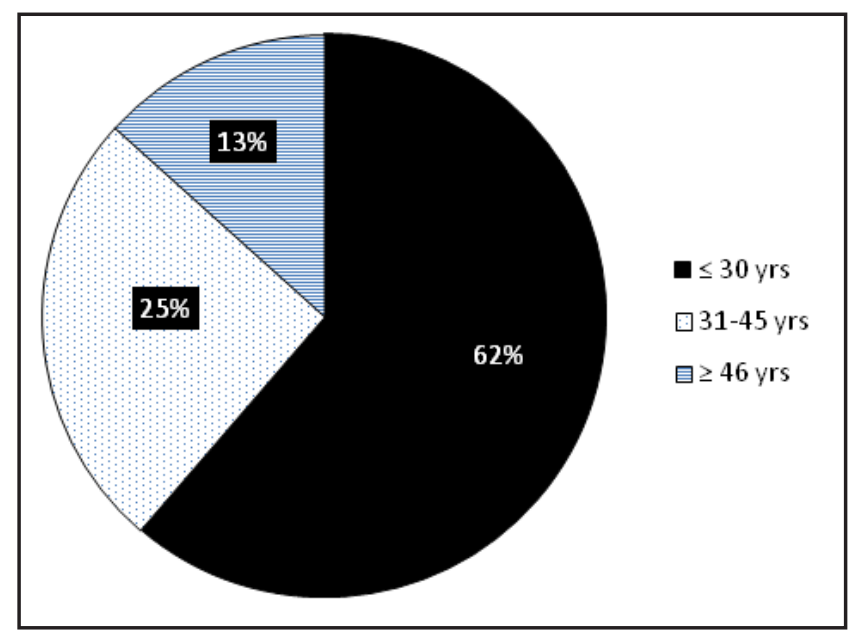

Fig 1. Distribution of the patients according to age group

Most frequent histopathological finding was Minimal Change Disease (MCD) ( $n=20 ; 26.7 \%)$ followed by $L N(n=16 ; 21.3 \%)$, Membranous Nephropathy (MN) ( $n=14 ; 18.6 \%)$, Focal Segmental Glomerulosclerosis (FSGS) ( $n=10 ; 13.4 \%)$ and IgA nephropathy (IgAN) ( $n=7 ; 9.3 \%)$. In others category $(10.7 \%)$, there were MPGN, C1q Nephropathy, ANCA associated vasculitis and Chronic Kidney Disease (Fig 2). Out of 16 LN cases, 14 were of Class IV and other were one each of class III and combination of classes III and V. There were two samples that had crescents in the biopsy samples and both of them were of LN class IV.

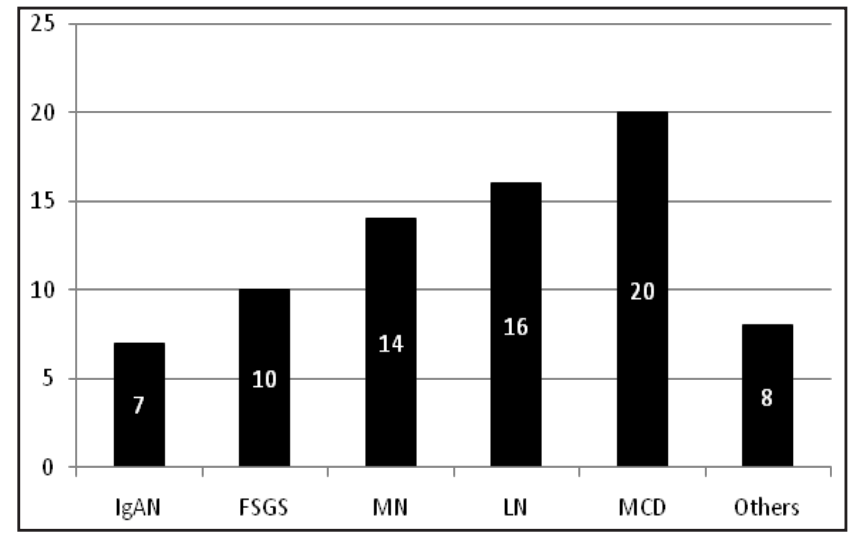

Fig 2. Bar diagram showing frequency of histological patterns in renal biopsy 
Patients with the histopathological diagnosis of LN and IgAN presented with hematuria in $81.2 \%$ and $71.4 \%$ respectively. MCD patients did not have hematuria, they presented with proteinuria only. MN and FSGS had hematuria in $42.8 \%$ and $40 \%$ respectively (Table: 1 ).

Table 1. Distribution of patients according to histopathological diagnosis and pre biopsy microscopic hematuria and proteinuria

\begin{tabular}{lccc}
\hline & $\begin{array}{c}\text { Microscopic } \\
\text { hematuria }\end{array}$ & $\begin{array}{c}\text { \% of patient with } \\
\text { hematuria }\end{array}$ & $\begin{array}{c}\text { Mean } \\
\text { Proteinuria }\end{array}$ \\
\hline MCD & 0 & 0 & $8.73 \pm 6.18$ \\
LN & 13 & 81.2 & $5.03 \pm 2.8$ \\
FSGS & 4 & 40 & $8.19 \pm 4.8$ \\
MN & 6 & 42.8 & $8.6 \pm 7.88$ \\
IgAN & 5 & 71.4 & $8.5 \pm 6$ \\
Others & 5 & 62.5 & $4.42 \pm 2.3$ \\
\hline
\end{tabular}

Total no. of glomeruli in the sample was $23.41 \pm 11.55$ (15.77 \pm 7.66 in LM and 7.96 \pm 5.83 in IF). Complications following biopsy were as shown in the table 2 .

Table 2. Post renal biopsy complications

\begin{tabular}{lll}
\hline \multicolumn{1}{c}{ Complications } & No. & \multicolumn{1}{c}{$\%$} \\
\hline Macroscopic hematuria & 6 & 8 \\
Microscopic hematuria & 8 & 10.7 \\
Perinephric hematoma & 2 & 2.67 \\
Clot in bladder & 1 & 1.34 \\
Clot colic & 1 & 1.34 \\
\hline
\end{tabular}

We had total of 15 patients who had microscopic hematuria post biopsy, but seven had microscopic hematuria pre renal biopsy so we could not ascertain whether in these patients the appearance of hematuria was biopsy related. There were no cases that needed blood transfusion or had hypotension post renal biopsy. There was no death related with renal biopsy.

\section{DISCUSSION:}

Our biopsy series shows that MCD was a common histopathological finding followed by lupus nephritis. As our center is a referral center we may have had $20 \%$ of cases of LN. Our study population's average age was 31 years showing younger and productive age group of our country is suffering from kidney diseases. This is similar to other studies from Nepal. Average age was 30.6 years for males and 32.9 years for females in the study done by Aryal et al. ${ }^{7}$ In the study by Ghimire $M$ et al., the age of the study population was $30 y$ rs and around $84 \%$ were from the age group $<45$ years. ${ }^{8}$ In a study done by Khakurel_et al with 398 patients in Nepal with or without IF examination of renal tissue, mean age was 28 years. ${ }^{9}$ Most of our patients were admitted with the diagnosis of nephrotic syndrome in our study which was consistent with other studies. ${ }^{7,9,10,11}$ As this was a retrospective study some patients' clinical diagnoses were not clearly written in the forms.

There is a slight predominance of female in our study which is consistent with a study done by Ghimire $\mathrm{M}$ et al. ${ }^{8}$ In both the studies there is a higher percentage of $L N$ cases. But this was not consistent with the studies done by Aryal et $\mathrm{al}^{7}$ and Sharma A et $\mathrm{al}^{11}$, where $\mathrm{LN}$ cases were few.

Regarding the pattern of the histological diagnosis, there were quite difference in distribution within and outside the country. In our study, MCD was the most common finding but Sharma A et al and Aryal G study showed MN as the common histological finding in their study. ${ }^{7,11}$ Khakurel et al reported as MCD being most common finding in those patients who had undergone both LM and IF examinations and in Kidney biopsy without IF, mesangial proliferative GN (MesPGN) was commonest. ${ }^{9}$ Increased no. of MCD in our series may have been due to absence of Electron microscopy examination of the samples. $\mathrm{MN}$ was second commonest disease in our study. In the study by Ghimire $M$, MesPGN was the most common histological finding and MCD was second commonest. ${ }^{8}$ In Korea (15\%) and China (13\%), MCD was second and third common disease respectively. ${ }^{6,12}$ Likewise, in a study done in Romania, MCD was the third commonest disease with $8.5 \% .{ }^{10}$ In Thailand, MCD comprised of $45.8 \%$ of total primary glomerular diseases. ${ }^{13}$ IgAN was the most common histological finding in Korea and China. ${ }^{6,12}$ In contrary to the trend of prevalence of IgAN in Asian countries, our study IgAN was present in $9.3 \%$ only. The studies from other parts of Nepal also shows similar trend of prevalence of IgAN as ours. ${ }^{8,9,11}$ This may show that diagnosis of IgAN may be underdiagnosed in Nepal because of possible conservative practice in performing renal biopsy, absenceof screening program and widespread unavailability of facilities. FSGS was the second most common disease in the study done by Khakurel $S$ et al and Sharma A et al, while it was fourth common cause of glomerular disease in our study. ${ }^{9,11}$ In the world, African countries, India and Brazil have more incidences of FSGS. ${ }^{14,15,16}$

We had a good no. of glomeruli, it is said that for a good interpretation of renal tissue, a sample should have atleast 10 glomeruli. ${ }^{17}$ Waldo $B$ et al showed in their study that absence of perinephric bleeding within an hour of post biopsy was predictive of an uncomplicated course while the presence of a perinephric haematoma was not reliably predictive of a clinically significant complication post-renal biopsy. ${ }^{18}$ We routinely did post renal biopsy USG to look for any complications but after $24 \mathrm{hrs}$ of biopsy in our cases. 
Complications in our series were few and comparable with other studies. Macroscopic hematuria was seen in $8 \%$ and microscopic hematuria was seen in $10.6 \%$. However, microscopic hematuria was seen in 15 patients but as there were seven patients amongst these who had hematuria prior to the renal biopsy so we could not ascertain whether in these patients the appearance of hematuria was biopsy related. Perinephric hematoma was seen in only $2.6 \%$. In the study of Ghimire $\mathrm{M}$ et al, the complications like macroscopic hematuria and perinephric hematoma were seen in $6.7 \%$ and $5.3 \%$ respectively but they did not look at the occurrence of microscopic hematuria. ${ }^{8}$ Mendelssohn and Cole found an overall complication rate of $5.3 \%$ in their series. ${ }^{19}$ Burnstein et al reported complications in $14.3 \%$ of 91 patients, out of which $6.6 \%$ were minor (microhematuria not requiring transfusion) and rest were major. ${ }^{20}$ Study from Romania showed that serious complications were observed most frequently when a large fragment was harvested (>20 glomeruli) and they had gross hematuria in $8.1 \%$, hemorrhage with hypotension in $2.4 \%$ and hematoma with hypotension in $0.9 \% .{ }^{10}$ Though in our study we had total no. of glomeruli of 23 , we did not have major complications requiring intervention. The complications may also be related with no. of pricks for harvesting the biopsy tissue and as this was a retrospective study we haven't documented in our study how many pricks were done on each patient. However, in our institute we do not recommend pricking for more than 3 to 4 times for harvesting the tissue.

This study further emphasizes that the histological pattern of the glomerular diseases depends on age, sex, race, geographical distribution and indication of kidney biopsy and it changes with the time. Our study has few limitations like it being a retrospective study and the biopsy samples not being examined with electron microscopy. At the time of this study our country did not have immunofluorescence test so all the samples were sent to India for examination in appropriate preservatives and we had to wait for more than 10 days on an average for the report. It is a very high time that we need a renal biopsy registry which is not available in Nepal and need to have more liberal indications for renal biopsy.

In conclusion, Nephrotic syndrome was the most common indication for the renal biopsy. MCD was the most common histological finding in our series and Lupus nephritis is not uncommon in our series. Complication of renal biopsy is uncommon and renal biopsy under USG guidance can be a safer procedure.

\section{REFERENCE:}

1. Pesce F, Schena FP. Worldwide distribution of glomerular diseases: the role of renal biopsy registries. Nephrol Dial Transplant 2010;25:334-6.

2. Tompson CRV. Indications for renal biopsy in chronic kidney disease. Clinical Medicine 2003;3:513-6.

3. Whittier WL, Korbet SM. Timing of complications in percutaneous renal biopsy. J Am Soc Nephrol 2004;15:142-7.

4. Tuladhar AS, Shrestha A, Pradhan S et al. USG assisted and USG guided percutaneous renal biopsy at Nepal Medical College Teaching Hospital: A three and half years study. Nepal Med Coll J 2014;16:26-9.

5. Yesudas SS, Georgy NK, Manickam S. Percutaneous real-time ultrasound-guided renal biopsy performed solely by nephrologists: A case series. Indian J Nephrol 2010;20:137-41.

6. Chang JH, Kim DK, Kim HW et al. Changing prevalence of glomerular diseases in Korean adults: a review of 20 years of experience. Nephrol Dial Transplant 2009;24:2406-10 doi:10.1093/ndt/gfp091

7. Aryal G, Kafle RK. Hisopathological spectrum of

glomerular disease in Nepal: a seven-year retrospective study. Nepal Med Coll J 2008;10:126-8.

8. Ghimire M,Pahari B,Paudel N, Das G, Das GC,Sharma SK. Kidney Biopsy: An Experience from Tertiary Hospital. J Nepal Med Assoc 2014;52:707-12

9. Khakurel S, Agrawal RK, Hada R. Pattern of Glomerular Disease in Nepal: A Single-center Experience. Saudi J Kidney Dis Transpl 2015;26:833-8.

10. Covic A, Schiller A, Volovat $C$ et al. Epidemiology of renal disease in Romania: a 10 year review of two regional renal biopsy databases. Nephrol Dial Transplant 2006;21:419-24. doi:10.1093/ndt/gfi207.

11. Sharma A, Deo RK, Shahi RR. Pattern of glomerular disease in a tertiary care hospital in Nepal: A Shree Birendra Hospital experience. JCMS-Nepal 2011;7:48-52.

12. Zhou F, Zhao M, Zou W, Liu G, Wang H. The changing spectrum of primary glomerular diseases within 15 years: A survey of 3331 patients in a single Chinese centre. Nephrol Dial Transplant 2009;24:870-76.doi:10.1093/ ndt/gfn554

13. Parichatikanond $P$, Chawanasuntorapoj $R$, Shayakul $C$ et al. An analysis of 3,555 cases of renal biopsy in Thailand. J Med Assoc Thai 2006;89:S106-11. 


\section{| Original Article}

14. N, Boucar D, El Hadj Fary KA et al. Histopathological profiles of nephropathies in Senegal. Saudi J Kidney Dis Transpl 2003;14:212-4.

15. Chandrika BK. Non-neoplastic renal diseases in Kerala, India- analysis of 1592 cases, a two year retrospective study. Indian J Pathol Microbiol 2007;50:300-2.

16. Malafronte P, Mastroianni-Kirsztajn G, Betônico GN et al. Paulista Registry of glomerulonephritis: 5-year data report. Nephrol Dial Transplant; 2006;21:3098-105.

17. Geldenhuys $L$, Nicholson $\mathrm{P}$, Sinha $\mathrm{N}$ et al. Percutaneous native renal biopsy adequacy: a successful interdepartmental quality improvement activity. Canadian Journal of Kidney Health and Disease 2015;2:8. doi $10.1186 / s 40697-015-0043-z$

18. Waldo B, Korbet SM, Freimanis MG, Lewis EJ. The value of post-biopsy ultrasound in predicting complications after percutaneous renal biopsy of native kidneys. Nephrol Dial Transplant 2009;24:2433-39.doi: 10.1093/ ndt/gfp073.

19. Mendelssohn DC, Cole EH. Outcomes of percutaneous kidney biopsy, including those of solitary native kidneys. Am J Kidney Dis 1995; 26: 580-5.

20. Burstein DM, Korbet SM, Schwartz MM. The use of the automated core biopsy system in percutaneous renal biopsies. A comparative study. Amer J Kidney Dis 1993; 22:545-52.doi: 10.1016/S0272-6386(12)80927-9. 